www.jmscr.igmpublication.org

Index Copernicus Value: 79.54

ISSN (e)-2347-176x ISSN (p) 2455-0450

crossref DOI: https://dx.doi.org/10.18535/jmscr/v7i5.162

\title{
Laparoscopic Gastric Cancer Surgery: An Early Experience from a Developing World Country
}

\author{
Authors \\ Dr Tanveer Ahmad Yatoo, Dr Abdul Rashid Ganaie, Prof. Iqbal Saleem Mir, \\ Dr Zahida Akhter, Prof. Farooq Ahmad Reshi, Dr Zaheem, Dr Aftab Akbar, \\ Dr Yaqoob, Dr Yasir Rehman \\ Post graduate, Department of General Surgery \\ Government Medical College, Srinagar, India
}

\section{Introduction}

Gastric cancer is one of the most common cancers worldwide. Asian countries like Japan, China, and South Korea have a high incidence; those with a low incidence include India, Pakistan, and Thailand ${ }^{1}$.Gastric cancer is the fourth common cancer and the second leading cause of cancer related deaths worldwide ${ }^{2}$. The age adjusted stomach cancer incidence among Kashmiri males was36.7/100,000 and among Kashmiri females was 9.9/100,000 in a study from 1986-1989. It indicated that there is a high rate of gastric cancer in Kashmiri population compared to other parts of the country ${ }^{3}$.

The first laparoscopy-assisted distal gastrectomy (LADG) for early gastric cancer (EGC) was reported in 1994. Since then there have been major breakthroughs in the field of gastric cancer surgery ${ }^{4}$ Understanding the comparative effectiveness of laparoscopic and open approaches to resection of early-stage gastric cancer is an important issue in the surgical management of this condition $^{5}$. There has been a tremendous improvement in laparoscopic approach with the use of endoscopic staplers making intracorporeal anastomosis feasible and much easier than before. Many studies showed long term results of laparoscopic gastric surgeries are comparable with those of open gastrectomy ${ }^{6-8}$.

\section{Objectives}

The aim of this study was to evaluate the results of laparoscopic surgeries in gastric carcinoma in a selected Kashmiri population.

\section{Material and Methods}

This prospective study was conducted in the Department of General Surgery, Government Medical College, Srinagar over a period of 3 years. Patients were given free choice to undergo either laparoscopic or open resection. Patients were excluded from study if metastasis was detected preoperatively or intra-operatively.

A total number of 30 patients who underwent laparoscopic gastric surgeries for carcinoma stomach were enrolled in the study after a written informed consent in local language.

Surgical Procedure: Stomach washes and bowel preparation was given to all patients. Procedure was carried out under general anaesthesia. The 
patients were placed on table in supine position with legs apart and $20^{\circ}$ head up tilt. Chief Surgeon operated the patients by standing between the legs with camera assistant on his left. Pneumoperitoneum was created by using veress needle by closed method. Diagnostic laparoscopy was done to rule out adjacent organ invasion and peritoneal seeding. Three other trocars of varying sizes were inserted through the abdominal wall, one upper left quadrant, one right upper quadrant and one in the midline just below the xyphoid process. After assessing the resectability, operative choice was based on location of tumour in stomach. Twenty seven patients underwent laparoscopic assisted distal partial gastrectomy with 5-6 cm tumor free resection margin grossly in distal gastic carcinoma and bilroth II type gastrojejunostomy reconstruction was done. Laparoscopic assisted total gastrectomy with Roux-en-Yoesophagojejunostomy was done in two patients for growth located in body of stomach and laparoscopic assisted proximal gastrectomy with oesophagogastrostomy in one patient for growth at cardia.

Procedures were performed with due respect to oncological principle and standard methods of dissection and ligation of major vessels using haemolockclips and harmonic scalpel where-ever needed. The resected specimen was extracted by extension of port site incision, taking due care not to spill the malignant cells during the extraction by using wound protectors and double glove technique.

For stage grouping current tumor node metastasis system classification was used.

Follow Up: All complications were closely monitored and in-hospital mortality, i.e. death within 30 days of procedure or during hospital stay were noted.

The patients were assessed for time to first flatus and time to first soft diet and postoperative hospital stay.

The patients who were discharged alive were followed after $1^{\text {st }}$ week, 1 month, then 3 monthly for $1^{\text {st }}$ year and 6 monthly thereafter.

\section{Results}

In our study, out of a total of 30 patients 23 (76.66\%) were males and $7(23.33 \%)$ were females. Majority of our patients i.e. 17 (56.66\%) were 61-70 years of age, followed by 10 (33.3\%) aged 51-60 years while as $3(10 \%)$ patients aged $\leq 50$ years. Abdominal pain / discomfort were the symptoms at presentation in majority of our patients i.e. $21(70 \%)$ followed by weight loss in $18(60 \%)$ and post prandial fullness in 16 $(53.33 \%)$. Early satiety and anorexia were found in $14(46.66 \%)$ patients and haematemesis/malena constituting $11(36.66 \%)$ patients. In general physical examination pallor was present in 12 $(40 \%)$ patients with oedema in $2(6.66 \%)$ patients.

\begin{tabular}{|l|c|c|}
\hline \multicolumn{2}{|l|}{ Patient Characteristics } \\
\hline \multirow{2}{*}{ Gender } & Male & $7(23.33 \%)$ \\
\cline { 2 - 3 } & Female & $23(76.66 \%)$ \\
\hline Age+SD (Years) & Abdominal pain & $21(70 \%)$ \\
\hline \multirow{4}{*}{$\begin{array}{l}\text { Presenting } \\
\text { symptoms }\end{array}$} & Weight loss & $18(60 \%)$ \\
\cline { 2 - 3 } & $\begin{array}{c}\text { Postprandial } \\
\text { fullness }\end{array}$ & $16(53.33 \%)$ \\
\cline { 2 - 3 } & $\begin{array}{c}\text { Early satiety / } \\
\text { anorexia }\end{array}$ & $14(46.66 \%)$ \\
\cline { 2 - 3 } & $\begin{array}{c}\text { Hematemesis / } \\
\text { malena }\end{array}$ & $11(36.66 \%)$ \\
\hline \multirow{2}{*}{ Signs } & Pallor & $12(40 \%)$ \\
\cline { 2 - 3 } & Edema & $2(7.66 \%)$ \\
\hline
\end{tabular}

On esophagogastroduodenoscopy (EGD), polypoid growth in stomach was seen in 17 (56.66\%) patients, ulcerative lesion in stomach was seen in $13(43.33 \%)$ patients. On CECT abdomen $23(76.66 \%)$ were found to have stomach growth, $7(23.3 \%)$ had stomach thickening while as $13(43.33 \%)$ patients was having perigastric lymphnodes. In our study, tumor was located in antrum in 17 (56.66\%) patients. Six $(20 \%)$ patients had tumour in pylorus, followed by $4(13.33 \%)$ in mid body, followed by. 2(6.66\%) in proximal body and one at gastroesophageal junction. Laparoscopic distal partial gastrectomy was the procedure done in 23 (76.66\%) of our patients while as $4(13.33 \%)$ patients under subtotal gastrectomy. Bilroth II reconstruction was done in these patients. Total gastrectomy with Roux-en-Y 
esophagojejunostomy was done in $2(6.66 \%)$ patients with growth in proximal body and proximal gastrectomy with esophagogastrostomy was done in $1(3.33 \%)$ patient.

\begin{tabular}{|l|c|}
\hline \multicolumn{2}{|l|}{ Operative Procedure } \\
\hline $\begin{array}{l}\text { Laparoscopic distal partial Gastrectomy } \\
\text { with Bilroth II reconstruction }\end{array}$ & $23(76.66 \%)$ \\
\hline $\begin{array}{l}\text { Laparoscopic subtotal distal Gastrectomy } \\
\text { with Bilroth II reconstruction }\end{array}$ & $4(13.33 \%)$ \\
\hline $\begin{array}{l}\text { Laparoscopic assisted total Gastrectomy } \\
\text { with Roux-en-Y esophagojujenostomy }\end{array}$ & $2(6.66 \%)$ \\
\hline $\begin{array}{l}\text { Laparoscopic assisted proximal } \\
\text { Gastrectomy with oesophagogastrostomy }\end{array}$ & $1(3.33 \%)$ \\
\hline
\end{tabular}

Mean volume of blood loss (ml) was 109.6+41.72. None of our patient's required intraoperative blood transfusion while as one $(3.33 \%)$ patient needed blood transfusion postoperatively. Mean duration of surgery (min) was $221.8 \pm 17.03$. In took a mean 3.1 days for our patients to first flatus. Liquid diet was started in(mean) 3.7 days while they resumed soft diet in (mean) 5.3 days. The complications noted were intra-luminal bleeding in $1(3.33 \%)$ patients, myocardial infarction in $1(3.33 \%)$, gastric stasis in $2(6.66 \%)$. Only one of our patient died in hospital. Out of a total of 29survived patients, $26(89.65 \%)$ required hospital stay for more than or equal to 7 days while as $3(10.34 \%)$ patients needed $<7$ days hospital stay. Papillary adenocarcinoma, tubular adenocarcinoma, mucinous adenocarcinoma, signet ring adenocarcinoma were the morphology of tumour in 11 (37.93\%), 15 (51.72\%), 2 (6.89\%) and $1(3.44 \%)$ patients. Surgical margin free (RO) was obtained in all cases with an average 17 number of dissected lymphnode ranging from 1229 nodes.

Recurrence of disease was seen in $5(17.24 \%)$ patients within one year. Peritoneal metastasis was found in $3(10.34 \%)$ patients on followup CECT abdomen with distant or haematogenus spread in 1 (3.44\%) patient. Esophagogastroduodenoscopy (EGD) was suggestive of recurrence at anastomosis in $1(3.44 \%)$ patient.

\begin{tabular}{|c|c|c|}
\hline \multicolumn{3}{|l|}{ Outcome } \\
\hline \multicolumn{2}{|c|}{ Operative time (mean+SD) } & $221.8 \pm 17.03 \mathrm{~min}$. \\
\hline \multicolumn{2}{|c|}{ Intraoperative blood loss (mean \pm SD) } & $109.6 \pm 41.72 \mathrm{ml}$ \\
\hline \multirow{2}{*}{$\begin{array}{l}\text { Resumption } \\
\text { orals (mean) }\end{array}$} & Liquid diet & 3.7 days \\
\hline & Soft orals & 5.3 days \\
\hline \multicolumn{2}{|l|}{ Intraluminal bleeding } & $1(3.33 \%)$ \\
\hline \multicolumn{2}{|l|}{ Gastric stasis } & $2(6.66 \%)$ \\
\hline \multirow{2}{*}{$\begin{array}{l}\text { Hospital stay in } \\
\text { days }\end{array}$} & $<7$ & $3(10.34 \%)$ \\
\hline & $\geq 7$ & $26(89.65 \%)$ \\
\hline \multicolumn{2}{|c|}{ In-hospital mortality } & $1(3.33 \%)$ \\
\hline
\end{tabular}

\begin{tabular}{|l|c|c|}
\hline Follow up (n=29) & \multicolumn{1}{|c|}{$\begin{array}{c}\text { Tubular } \\
\text { adenocarcinoma }\end{array}$} & $15(51.72 \%)$ \\
\hline Histopathology & $\begin{array}{c}\text { Papillary } \\
\text { adenocarcinoma }\end{array}$ & $11(37.93 \%)$ \\
\hline & $\begin{array}{c}\text { Mucinous } \\
\text { adenocarcinoma }\end{array}$ & $2(6.89 \%)$ \\
\hline & Signet ring cell & $1(3.44 \%)$ \\
\hline Surgical free margins & dissected & $29(100 \%)$ \\
\hline Median lymph node d & $\begin{array}{c}\text { Peritoneal } \\
\text { metastasis }\end{array}$ & $3(10.34 \%)$ \\
\hline Recurrence (n=5) & Distant metastasis & $1(3.44 \%)$ \\
\hline & $\begin{array}{c}\text { Anastomosis } \\
\text { recurrence }\end{array}$ & $1(3.44 \%)$ \\
\hline & Stage I & $3(10.34 \%)$ \\
\hline Staging & Stage II & $14(48.27 \%)$ \\
\hline \multicolumn{2}{|c|}{ Stage III (A) } & $10(34.48 \%)$ \\
\hline & Stage III (B) & $2(6.89 \%)$ \\
\hline
\end{tabular}

\section{Discussion}

Since the first published report regarding laparoscopic gastrectomy for early gastric cancer ${ }^{9}$, many retrospective studies and small randomized clinical trials have shown the short-term benefits of laparoscopic gastrectomy over open conventional surgery and long-term outcomes that are comparable between the two ${ }^{10-15}$. Several meta-analyses also confirm that laparoscopic gastrectomy is an equivalent method to conventional open surgery ${ }^{16-19}$. Laparoscopic gastrectomy for gastric adenocarcinoma has evolved due to the advent of new technologies and improved surgical techniques.

In our study majority of our patients were 61-70 years. Males were more than females. Abdominal pain / discomfort were the main symptoms at presentation followed by weight loss and post prandial fullness. On general physical examination pallor was present in majority of patients followed by oedema. On 
esophagogastroduodenoscopy (EGD), polypoid growth in stomach was seen in majority of patients.On CECT abdomen stomach growth was found in majority of cases followed by stomach thickening. Our findings were consistent with several other studies ${ }^{20-26}$.

Several authors have reported successful laparoscopic subtotal or total gastrectomy, demonstrating the important postoperative advantages of this procedure ${ }^{27-35}$. Radical surgical resection of the tumor is the only hope for cure in these patients. ${ }^{36}$ Total gastrectomy has been advocated for proximal and middle stomach cancer. However, for distal gastric cancer, results have been similar for total and subtotal gastrectomy and the latter is now the operation of choice when the tumor is located in the distal part of the stomach. ${ }^{37,38}$ In our study, in majority of cases (23 patients) distal gastrectomy was the procedure done, while as subtotal gastrectomy was done 4 patients, total gastectomy in 2 patients and proximal gastrectomy in 1 patient .

Mean volume of blood loss (ml) was 109.6 \pm 41.72 . None of our patients required intraoperative blood transfusion while as one $(3.33 \%)$ patient needed blood transfusion postoperatively. Mean duration of surgery (min) was $221.8 \pm 17.03$. Junhyun Lee et al $(2012)^{39}$ in a study determined an estimated blood loss $(\mathrm{ml})$ of $131.0 \pm 77.6$ and the estimated period of surgery in minute was $212.5+43$, which is comparable to our study.

Liquid diet was started in (mean) 3.7 days while they resumed soft diet in (mean)5.3 days. Feng LM et al $(2013)^{40}$ conducted a clinical analysis of 25 gastric cancer cases undergoing totally laparoscopic distal gastrectomy and found that mean time to the first flatus was $(2.8 \pm 1.2$ days) and mean time liquid diet to resume was (3.5 \pm 0.9 days). Intra-luminal bleeding was seen in $1(3.33 \%)$ patients, myocardial infarction in 1 (3.33\%), gastric stasis in $2(6.66 \%)$. Only 1 of our patient died in hospital. Junhyun Lee et al (2012) ${ }^{39}$ in their study observed that intraluminal bleeding was the complication in $4(3.1 \%)$, gastric stasis in $2(1.5 \%)$. Out of a total of 29 studied patients, 26
$(89.66 \%)$ required hospital stay for more than or equal to 7 days while as $3(10.34 \%)$ patients needed $<7$ days hospital stay. Hospital stay in days was 9 days (range 7-12 days) in a study done by Han SM et al (2004) ${ }^{41}$. Surgical margin free (RO) was obtained in all the cases with 17 number of dissected lymphnode (median). Recurrence of disease was seen in $5(16.66 \%)$ patients. Peritoneal metastasis was found in $3(10 \%)$ patients on follow up CECT abdomen with distant or haematogenus spread in 1 (3.3\%) patient. Esophagogastro-duodenoscopy (EGD) was suggestive of recurrence at anastomosis in 1 (3.3\%) patient. Pan $\mathrm{H}$ et al $(2017)^{42}$ in their study observed recurrence in 153 (13\%) patients. Out of 23 patients in D1 group, 6 patients developed recurrence. EGD detected anastamotic recurrence in all 6 patients.

\section{Conclusion}

Our experience suggests that laparoscopic gastric surgeries has several advantages including less surgical trauma, less intraoperative blood loss, less pain, early postoperative recovery, decreased hospital stay without compromising the oncological principles with better cosmesis and patient compliance.

\section{Bibliography}

1. Parkin DM, Bray FI, Devesa SS. Cancer burden in the year 2000. The global picture. Eur J Cancer 2001;37:S4-S66.

2. Peter Boyle, Bernard Levin (eds.) (2008). World Cancer Report2008, IARC, Lyon 2008.

3. Khuroo MS, Zargar ZA, Mahajan R, et al (1992). High incidence of esophageal and gastric cancer in Kashmir - in a population with special personal and dietary habit. Gut, 33, 11-5.

4. Kitano S, Iso Y, Moriyama M, Sugimachi K. Laparoscopy-assisted Billroth I gastrectomy. Surg Laparosc Endosc 1994:4:146-148 
5. Kinoshita T, Shibasaki H, Oshiro $\mathrm{T}$, Ooshiro M, Okazumi S, et al. (2011) Comparison of laparoscopy-assisted and total laparoscopic Billroth-I gastrectomy for gastric cancer: A report of short-term outcomes. SurgEndosc 25: 1395-1401.

6. Vinuela EF, Gonen M, Brennan MF, Coit DG, Strong VE. Laparoscopic Distal Gastrectomy for Gastric Cancer. Laparoscopic versus open distal gastrectomy for gastric cancer: a metaanalysis of randomized controlled trials and high-quality nonrandomized studies. Ann Surg 2012;255:446-456.

7. Zeng YK, Yang ZL, Peng JS, Lin HS, Cai L. Laparoscopy-assisted versus open distal gastrectomy for early gastric cancer: evidence from randomized and nonrandomized clinical trials. Ann Surg 2012;256:39-52.

8. Jiang L, Yang KH, Guan QL, et al. Laparoscopy-assisted gastrectomy versus open gastrectomy for resectable gastric cancer: an update meta-analysis based on randomized controlled trials. SurgEndosc 2013;27:2466-2480.

9. Kitano S, Iso Y, Moriyama M, Sugimachi K. Laparoscopy-assisted Billroth I gastrectomy. Surg Laparosc Endosc 1994; 4: 146-148.

10. Kitano S, Shiraishi N, Fujii K, Yasuda K, Inomata M, Adachi $\mathrm{Y}$. A randomized controlled trial comparing open vslaparoscopyassisted distal gastrectomy for the treatment of early gastriccancer: an interim report. Surgery 2002; 131: S306S311

11. Kim HH, Hyung WJ, Cho GS, Kim MC, Han SU, Kim W, RyuSW, Lee HJ, Song KY. Morbidity and mortality of laparoscopic gastrectomy versus open gastrectomy for gastric cancer: an interimreport--a phase III multicenter, prospective, randomized Trial(KLASS
Trial). Ann Surg 2010; 251: 417-420 [PMID: 20160637.

12. Hayashi H, Ochiai T, Shimada H, Gunji Y. Prospective randomized study of open versus laparoscopy-assisted distal gastrectomy with extra perigastric lymph node dissection for early gastric cancer. Surg Endosc 2005; 19: 1172-1176

13. Huscher CG, Mingoli A, Sgarzini G, Sansonetti A, Di Paola M,Recher A, Ponzano C. Laparoscopic versus open subtotal gastrectomy for distal gastric cancer: five-year results of a randomized prospective trial. Ann Surg 2005; 241: 232-237

14. Lee SI, Choi YS, Park DJ, Kim HH, Yang HK, Kim MC .Comparative study of laparoscopy-assisted distal gastrectomy andopen distal gastrectomy. J Am Coll Surg 2006; 202: 874-880.

15. Lee JH, Yom CK, Han HS. Comparison of long-term outcomes of laparoscopyassisted and open distal gastrectomy for early gastric cancer. Surg Endosc 2009; 23: 1759-1763 [PMID: 19057958.

16. Viñuela EF, Gonen M, Brennan MF, Coit DG, Strong VE.Laparoscopic versus open distal gastrectomy for gastric cancer:a meta-analysis of randomized controlled trials and high-quality nonrandomized studies. Ann Surg 2012; 255: 446-456.

17. Memon MA, Khan S, Yunus RM, Barr R, Memon B. Metaanalysisof laparoscopic and open distal gastrectomy for gastriccarcinoma. Surg Endosc 2008; 22: 1781-1789 [PMID: 18437472.

18. Kodera Y, Fujiwara M, Ohashi N, Nakayama G, Koike M, MoritaS, Nakao A. Laparoscopic surgery for gastric cancer: a collectivereview with metaanalysis of randomized trials. J Am CollSurg2010; 211: 677-686.

19. Zorcolo L, Rosman AS, Pisano M, Marcon F, Restivo A, Nigri GR,Fancellu A, Melis M. A meta-analysis of prospective 
randomized trials comparing minimally invasive and open distal gastrectomy for cancer. J Surg Oncol 2011; 104: 544-551.

20. Lewis, W.G., Edwards, P., et al. D2 or Not D2? The Gastrectomy Question. Gastric Cancer, 2002; 5: 29-34.

21. Cristiano G.S. Huscher, Andrea Mingoli, Giovanna Sgarzini, Andrea Sansonetti, Massimiliano Di Paola, AchilleRecher, and Cecilia Ponzano. Laparoscopic Versus Open Subtotal Gastrectomy for Distal Gastric Cancer: Five-Year Results of a Randomized Prospective Trial. Annals of Surgery 2005 Feb; Vol. 241, No. 2: Page 232-37.

22. Junhyun Lee, Dongjin Kim, Wook Kim. Comparison of laparoscopy-assisted and totally laparoscopic Billroth-II distal gastrectomy for gastric cancer. J Korean Surg 2012; 82: 135-142.

23. Alfar Nafae, Raiees Ahmad, Amber Aliya, YawarNisar, Pervaze Salam, Imtiyaz Ahmad. D1 versus modified D2 gastrectomy for $\mathrm{Ca}$ stomach - A prospective and comparative study. Scientific Research 2016 Jan; Vol. 7, No. 1 .

24. Wanebo HJ, Kennedy BJ, Chmiel J, Steele G, Winchester D, and Osteen R. Cancer of the Stomach A Patient Care Study by the American College of Surgeons. Annals of Surgery 1993; Vol. 218, No. 5: Page 583592.

25. Degiuli, M., Sasako, M., Ponti, A., Soldati, T., Danese, F. and Calvo, F. Morbidity and Mortality after Modified D2 Gastrectomy for Gastric Cancer: Results of the Italian Gastric Cancer Study Group Prospective Multicenter Surgical Study. Journal of Clinical Oncology, 1998; 16: 1490-1493.

26. Huang CM, LinJX, ZhengCH, LiP, XieJWandWangJB. Impact of the Number of Dissected Lymph Nodes on Survival for Gastric Cancer after Distal Subtotal
Gastrectomy. Gastroenterology Research and Practice, 2011, Article ID: 476014.

27. Kitano S, Adachi Y, Shiraishi N, et al. Laparoscopic-assisted proximal gastrectomy for early gastric carcinomas. Surg Today. 1999;29:389-391.

28. Shiraishi N, Adachi Y, Kitano S, et al. Indication for and outcome of laparoscopic-assisted Billroth I gastrectomy. Br J Surg. 1999;86:541-544.

29. Adachi Y, Suematsu T, Shiraishi N, et al. Quality of life after laparoscopic-assisted Billroth I gastrectomy. Ann Surg. 1999;229:49-54.

30. Adachi Y, Shiraishi N, Shiromizu A, et al. Laparoscopy-assisted Billroth I gastrectomy compared with conventional open gastrectomy. Arch Surg. 2000;135:806-810.

31. Kitano S, Shiraishi N, Fujii K, et al. A randomized controlled trial comparing open vs. laparoscopy-assisted distal gastrectomy for the treatment of early gastric cancer: an interim report. Surgery. 2002; 131(suppl):306-311.

32. Yano H, Monden T, Kinuta M, et al. The usefulness of laparoscopy assisted distal gastrectomy in comparison with that of open distal gastrectomy for early gastric cancer. Gastric Cancer. 2001;4:93-97.

33. Reyes CD, Weber KJ, Gagner M, et al. Laparoscopic vs open gastrectomy: a retrospective review. SurgEndosc. 2001;15: 928-931.

34. Asao T, Hosouchi Y, Nakabayashi T, et al. Laparoscopically assisted total or distal gastrectomy with lymph node dissection for early gastric cancer. $\mathrm{Br} \mathrm{J}$ Surg. 2001;88:128-132.

35. Azagra JS, Goergen M, De Simone P, et al. Minimally invasive surgery for gastric cancer. Surg Endosc. 1999;13:351-357.

36. Bonenkamp JJ, Hermans J, Sasako M, et al. Extended lymph-node dissection for 
gastric cancer. N Engl J Med. 1999; 340:908-914.

37. Cuschieri A. Gastrectomy for gastric cancer: definitions and objectives. $\mathrm{Br} \mathrm{J}$ Surg. 1986;73:513-514.

38. Hioki K, Nakane $\mathrm{Y}$, Yamamoto $\mathrm{M}$. Surgical strategy for early gastric cancer. Br J Surg. 1990;77:1330-1334.

39. Junhyun Lee, Dongjin Kim, Wook Kim. Comparison of laparoscopy-assisted and totally laparoscopic Billroth-II distal gastrectomy for gastric cancer. J Korean Surg 2012; 82: 135-142.

40. Feng LM, Li G, Zhahg HJ, Sun XC. Clinical analysis of 25 gastric cancer cases undergoing totally laparoscopic distal gastrectomy. Chinese Journal of Gastrointestinal Surgery 2013; 16(10): 966-969.

41. Han SM, Cha SW, Kim WW, Jeon HM. Totally laparoscopic distal gastrectomy with D1 $\square$ lymph node dissection. J Minim Invasive Surg, 2004; 7(2): 116-121.

42. Pan H, Li T, Huang Z, Yu H, Kong D, Pan C, Jiang Y. Laparoscopic versus open gastric surgery for the treatment of pathological T1N0M0 gastric cancer in elderly patients: a matched study. Sci Rep. 2017 May 15; 7(1): 1919. 